\begin{tabular}{|c|l|}
\hline Title & Minimally Invasive Surgical Treatment for Tuberculous Spondy lodiscitis \\
\hline Author(s) & Ito, M.; Sudo, H.; A bumi, K.; Kotani, Y.; Takahata, M.; Fujita, M.; Minami, A. \\
\hline Citation & $\begin{array}{l}\text { Minimally Invasive Neurosurgery, 52(5-6), 250-253 } \\
\text { https://doi.org/L0.1055/s0029-1220685 }\end{array}$ \\
\hline Issue Date & 2009-10 \\
\hline Doc URL & http://hdl.handle.net/2115/43943 \\
\hline Rights & ○ 2009 Georg Thieme Verlag KG \\
\hline Type & article (author version) \\
\hline File Information & MIN52-5-6_250-253.pdf \\
\hline
\end{tabular}

Instructions for use 


\section{Minimally Invasive Surgical Treatment for Tuberculous Spondylodiscitis}

M. Ito ${ }^{1}$, H. Sudo ${ }^{2}$, K. Abumi $^{1}$, Y. Kotani ${ }^{1}$, M. Takahata ${ }^{1}$, M. Fujita ${ }^{3}$, A. Minami ${ }^{1}$, MD

${ }^{1}$ Department of Orthopaedic Surgery, Hokkaido University Graduate School of Medicine, Sapporo, Japan

${ }^{2}$ Department of Advanced Medicine for Spine and Spinal Cord Disorders, Hokkaido University Graduate School of Medicine, Sapporo, Japan

${ }^{3}$ Department of Orthopaedic Surgery, Sapporo Teishin Hospital, Sapporo, Japan

Correspondence: Hideki Sudo, $\mathrm{MD}, \mathrm{PhD}$

Department of Advanced Medicine for Spine and Spinal Cord Disorders, Hokkaido

University Graduate School of Medicine, Sapporo, Japan

North-15, West-7, Kita-ku , Sapporo, Hokkaido 060-8638, Japan

Tel: 81-11-706-5934 Fax: 81-11-706-6054

Email: hidekisudo@yahoo.co.jp 


\section{Abstract}

The authors report cases of 3 patients with tuberculous spondylodiscitis. All patients suffered from severe back or low back pain. Posterolateral endoscopic debridement and irrigation was performed followed by retention of a drainage tube at the affected sites. Additional puncture and drainage was conducted at the same time when extensive cold abscesses were identified around the paravertebral muscle. All patients experienced immediate pain relief postoperatively. This technique is effective for rapid pain relief and in obtaining neurological resolution for patients in the early stages of tuberculous spondylodiscitis and may also be a good method of preventing further vertebral collapse and kyphotic spinal deformity such as Gibbus vertebrae.

\section{Key Words}

Minimally Invasive Surgery, Endoscopic surgery, Tuberculous Spondylodiscitis, posterolateral approach 


\section{Introduction}

With an increase in the numbers of patients with multiple medical problems such as immunodeficiency, metastatic cancer, or diabetic mellitus diseases in developed countries, there has been a notable increase in the number of tuberculous cases. Tuberculous spondylodiscitis is the most common and most dangerous form of skeletal tuberculosis and comprises approximately $50 \%$ of all cases of skeletal tuberculosis. ${ }^{1}$ The initial treatment usually starts with anti-tuberculous drugs and surgical treatment is indicated only when neurologic deficits have become clear and progressive. The standard surgical treatment method for tuberculous spondylodiscitis is adequate debridement of the infected sites, decompression for affected neural structures, and vertebral stabilization with a bone graft through an anterior and/or posterior approach. Although such open surgery has mostly been effective in alleviating pain and the neurologic deficits, it is sometimes too invasive for some elderly patients with poor general conditions due to multiple existing comorbidities. $^{2}$

We have been utilizing an endoscopic, minimally invasive treatment approach to treat tuberculous spondylodiscitis. The purpose of this study was to describe this surgical technique and report the preliminary results of the procedure. 


\section{Case Reports}

\section{Patient Population}

Three patients with tuberculous spondylodiscitis underwent posterolateral endoscopic debridement and irrigation between 2004 and 2005. All these patients had been diagnosed with lung tuberculosis before spine surgery and anti-tuberculous agents had already been instigated. Two patients were female and one patient was male. Their mean age was 40 (range 26-57 years). The surgical indications for this procedure are that there is minimal destruction of the vertebral body and the associated neurological deficits are less serious. All 3 patients had severe back or low back pain. Preoperative and postoperative pain response was evaluated by visual analog scale (VAS: 0-100mm). No patient showed neurological deficits. Clinical data are summarized in Table 1. In all patients, preoperative magnetic resonance imaging (MRI) revealed heterogeneous and focal post-contrast enhancement of the vertebral body and paraspinal abscess with rim enhancement. Radiographic evaluation was conducted to examine spinal fusion, progression of local kyphosis, and presence of epidural or psoas abscess.

Surgical Technique

The patient is placed prone on a U-shaped frame to decrease abdominal 
pressure and lumbar lordosis. Using an image intensifier, the site of the skin incision is determined. In order to access the entire intervertebral disc space, a guide needle is inserted 45 degrees obliquely to the vertical line targeting the center of the disc space under local anesthesia with fluoroscopic guidance (Figure1). This is followed by confirmation of no iatrogenic nerve injuries under endoscopy. The Yeung Endoscopic Spinal System (Richard Wolf Co., Illinois) and Surgitron IEC-3 (Ellman Japan, Osaka, Japan) are used for the entire procedure. This posterolateral spinal endoscopic approach is the same as that described by Yeung et al. ${ }^{3}$ The affected intervertebral disc and vertebral bodies are curetted and irrigated under continuous suction. When the patient felt considerable pain during the procedures, an appropriate dose of fentanyl or benzodiazepine is administrated via intravenous anesthesia. Flexible rongeurs help to remove both cranial and caudal infected vertebral bodies. These procedures were confirmed to avoid neurovascular injury by endoscopy at all times. A single portal approach is usually used for this procedure, however, biportal access may be chosen for more aggressive debridement if the infected lesion is large and within the spinal column. After the debridement, pressurized irrigation with more than 2 liters saline is carried out. Finally, a $5 \mathrm{~mm}$ diameter drainage tube is retained in the affected sites at either single or 
bilateral sides. The drainage tube is retained until the amount of the excess fluid decreased to 5-10 ml / day. Additional computed topography-guided puncture and drainage may be conducted at the same time when extensive cold abscesses are identified around the paravertebral muscle. ${ }^{6}$ The patients are encouraged to stand up and walk the day after surgery with a hard brace for 3 to 6 months. 


\section{Results}

Mycobacterium tuberculosis was isolated in all cases. Back or low back pain disappeared or decreased in all patients. Averaged VAS for back or low back pain before surgery was 70 and 28 at postoperative one week (Table 1). Averaged VAS at the final follow-up was 5. No treatment side effects were apparent. The follow-up period ranged from 24 to 40 months (mean 33 months). The mean period during which the drainage tube remained in place was 68 days (range 10- 180 days). The administration of anti-tuberculous agents was continued for a mean of 16 months until remission was confirmed by relief of back or low back pain, decreasing CRP revels, and resolution of lung tuberculosis. At the final follow-up examination, all laboratory data returned to within the normal limits. Postoperative follow-up using plain radiographs did not show further collapse of the vertebral body in all patients. MRI in all patients revealed spontaneous fusion between adjacent vertebrae with organized, small paravertebral abscess. Epidural abscess compression of the spinal cord was resolved in all cases.

Illustrative Case

This 26-year-old woman was referred with a 3-month history of lung 
tuberculosis. She had suffered significant back pain. She also noticed a tingling sensation, tightness, and an aching pain in both her legs. The peripheral white blood cell count was $9800 / \mathrm{mm}^{3}$, and her C-reactive protein level was $0.59 \mathrm{mg} / \mathrm{dl}$. Plain radiographs of the spine showed destruction of endplate of vertebral body at the T11/12 level. Enhanced MRI of the spine showed heterogeneous and focal lesions in vertebral bodies and paraspinal abscess with rim enhancement (Figure2). She could not been treated either by further anti-tuberculous agents or major surgery such as anterior decompression followed by fusion because of supervened drug-induced acute hepatitis during the treatment her lung tuberculosis. She underwent endoscopic, minimally invasive treatment using a biportal approach. During the surgery, a creamy white abscess was observed through a tube inserted the intervertebral bodies. She noticed improvement of her symptoms immediately postoperatively. The drainage tubes were removed 14 days after surgery. After acute hepatitis was controlled, anti-tuberculosis drugs (isoniazid, ethambutol, and rifampicin) were re-administrated. These dugs were continued for 2 years after surgery. At the 3-year follow-up visit, her symptoms had completely disappeared and good bone fusion was observed. 


\section{Discussion}

Minimally invasive treatment for pyogenic spondylodiscitis has steadily become recognized. In 1991, Yu, et al., ${ }^{4}$ reported the first cases of osteomyelitis treated with nucleotome-based percutaneous suction aspiration. This procedure was performed under local anesthesia and good clinical results were reported. Tuberculosis was confirmed in one case and $C$. albicans was detected in another. Recently, Hanaoka, et al., ${ }^{2}$ reported good results treating the severe pyogenic spondylitis managed with percutaneous drainage and a continuous irrigation system. They suggested that these techniques could be considered a salvage treatment in patients with severe pyogenic spondylitis in whom conservative treatment had failed, particularly in patients with a poor general condition. We have used an endoscopic system to treat pyogenic spondylitis since 2001 and reported good clinical results. ${ }^{5}$ This technique has the advantage of reducing a potential risk of neurological damage and complications. More reliable curettage of infected lesions can be carried out associated with appropriate visualization.

One of the major complications of tuberculous spondylodiscitis is kyphotic deformity resulting form unstable vertebral collapse of the infected spine. Early diagnosis and prompt treatment are essential to prevent a permanent 
spinal kyphosis and any severe neurologic deficit. The procedure is effective for transforming the infected spine from an unstable condition to a more stable condition without the use of bone grafting and conventional open surgery. Moreover, epidural and paravertebral abscess originating from the anterior spinal column can also be successfully treated with this procedure. This procedure is also effective for preventing focal infection spread to other sites by reducing the internal pressure of the infected site. The major difference in this treatment regime for tuberculous spondylodiscitis compared with previous methods for pyogenic spondylodiscitis is that the treatment duration and use of drainage tube and antibiotic drugs is relatively longer than for of pyogenic spondylodiscitis. ${ }^{5}$ However, the clinical results were equally as good.

The best indicators for the use of this procedure are for the patient to have minimal or moderate destructive changes in the vertebrae in the early phase of tuberculous spondylodiscitis and a lack of improvement observed after conservative treatment with antibiotic therapy.

In conclusion, our experience suggests that this technique is effective for rapid pain relief and problem free neurological resolution during the early stages of tuberculous spondylodiscitis and may be a good method of preventing further vertebral collapse and kyphotic spinal deformity such as 
Gibbus vertebrae. 


\section{References}

1. Tuli SM, Srivastava TP, Varma BP, Varma BP, Sinha GP. Tuberculosis of spine. Acta Orthop Scand 1967;38: 445-458

2. Hanaoka N, Kawasaki Y, Sakai T, Nakamura T, Nanamori K, Nakamura E, Uchida K, Yamada H. Percutaneous drainage and continuous irrigation in patients with severe pyogenic spondylitis, abscess formation, and marked bone destruction. J Neurosurg Spine 2006;4: 374-379

3. Yeung AT, Tsou PM. Posterolateral endoscopic exicion for lumbar disc herniation. Surgical technique, outcome, and complications in 307 consecutive patients. Spine 2002; 27: 722-731

4. Yu MY, Siu C, Wing PC, Schweigel JF, Jetha N. Percutaneous suction aspiration for osteomyelitis: report of two cases. Spine 1991;16: $198-202$

5. Ito M, Abumi K, Kotani Y, Kadoya,K, Minami A. Clinical Outcome of Posterolateral Endoscopic Surgery for Pyogenic Spondylodiscitis: Results of 15 Patients with Serious Comorbid Conditions. Spine 2007;32:200-206 


\section{Figures legends}

\section{Figure 1.}

A. A guide needle is inserted 45 degrees obliquely to the vertical line targeting the center of the disc space under local anesthesia with fluoroscopic guidance. This is followed by confirmation of no iatrogenic nerve injuries under endoscopy. During the surgery, creamy white abscess was observed.

B. When the fibers of annulus fibrosis interfered with the scopic view, a radio frequency ablation device helped to shrink disc materials. These procedures were confirmed to avoid neurovascular injury by endoscopy at all times.

\section{Figure 2.}

Case2. MR images of the patient's spine at admission (Panel A) and final follow-up after the surgical treatment (Panel B). 
Table 1. Summary of 3 patients who underwent endoscopic surgery for tubercular spondylodiscitis

\begin{tabular}{|c|c|c|c|c|c|c|c|c|c|c|c|c|c|}
\hline \multirow[b]{2}{*}{ Case No. } & \multirow[b]{2}{*}{ Age(yrs)/Sex } & \multirow{2}{*}{$\begin{array}{c}\text { Vertebral } \\
\text { level }\end{array}$} & \multirow[b]{2}{*}{ Source } & \multirow[b]{2}{*}{ Complication } & \multirow[b]{2}{*}{ Symptoms } & \multirow{2}{*}{$\begin{array}{c}\text { Neurological } \\
\text { deficits }\end{array}$} & \multirow{2}{*}{$\begin{array}{c}\text { Preop } \\
\text { CPP(mg/dl) }\end{array}$} & \multicolumn{3}{|c|}{ VBS (mm) } & \multirow[b]{2}{*}{ FU (mos) } & \multirow{2}{*}{$\begin{array}{c}\text { Drainage } \\
\text { (days) }\end{array}$} & \multirow{2}{*}{$\begin{array}{c}\text { Anti TB } \\
\text { drugs (mos) }\end{array}$} \\
\hline & & & & & & & & Preop & Postop (1w) & Final & & & \\
\hline 1 & $37 / M$ & $\mathrm{~L} 2 / 3,3 / 4$ & Lung TB & None & LBP & None & 9.09 & 60 & 20 & 0 & 40 & 180 & 12 \\
\hline 2 & $26 / / F$ & $\mathrm{~T} 10, \mathrm{~T} 11 / 12$ & Lung TB & Drug induced hepatitis & Back pain/leg pain & None & 0.59 & 70 & 30 & 0 & 36 & 14 & 24 \\
\hline 3 & $57 / \mathrm{F}$ & $\mathrm{L} 3 / 4$ & Lung TB & None & LBP & None & 0.24 & 80 & 35 & 15 & 24 & 10 & 12 \\
\hline
\end{tabular}

$\mathrm{TB}=$ tuberculosis; $\mathrm{LBP}=$ low back pain; $\mathrm{VAS}=$ visual analog scale; $\mathrm{FU}=$ follow-up 



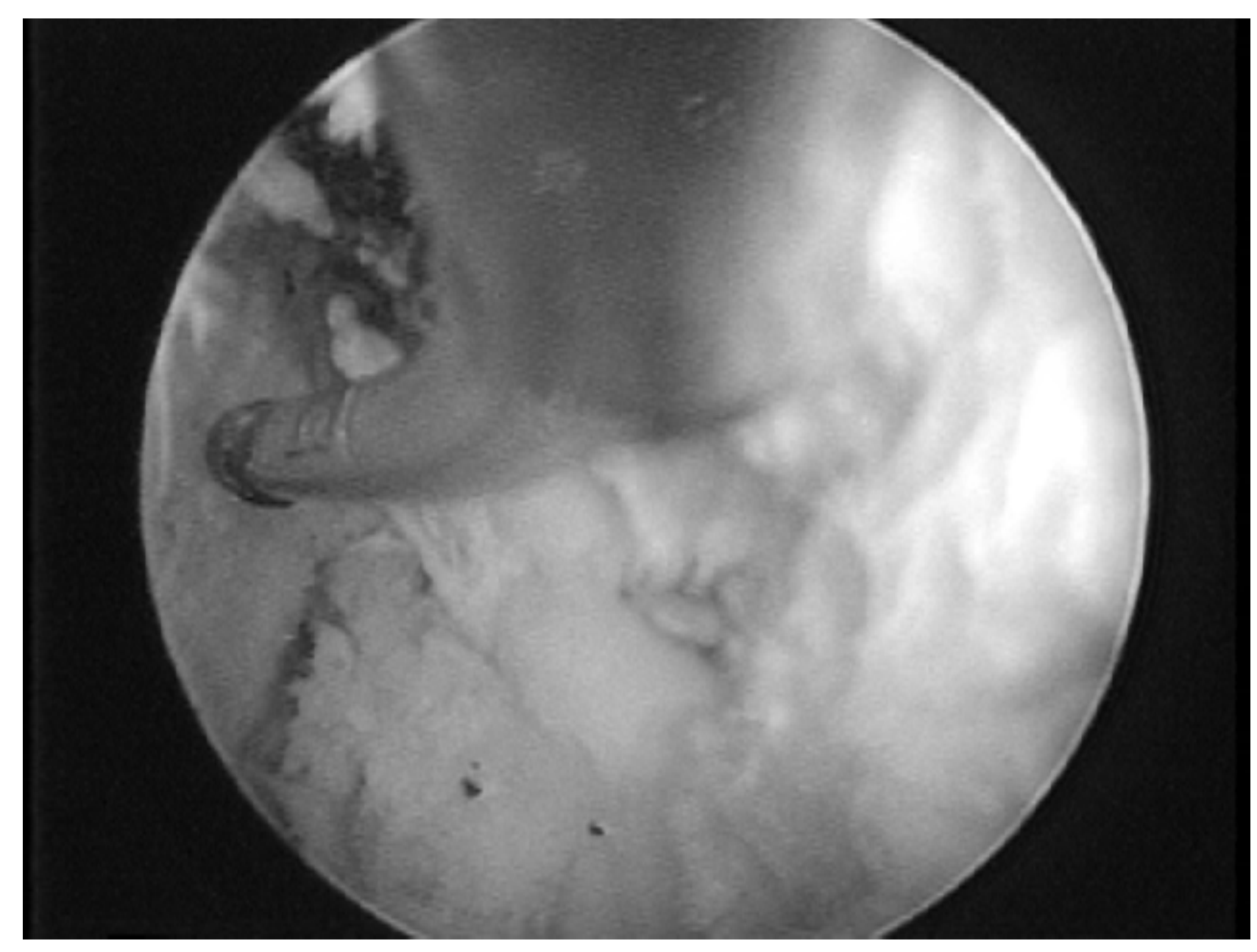

Fig 1B 


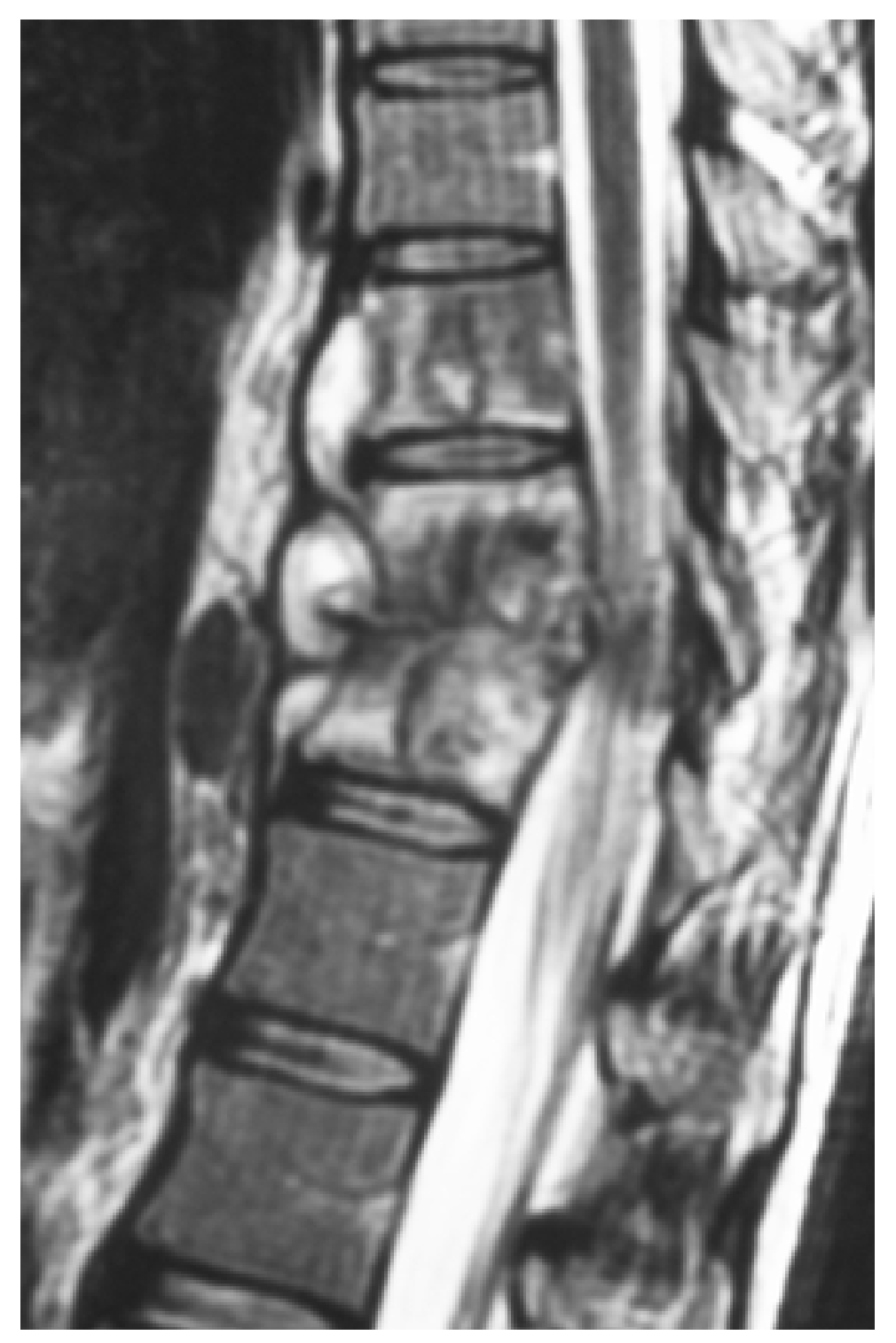

Fig 2A 


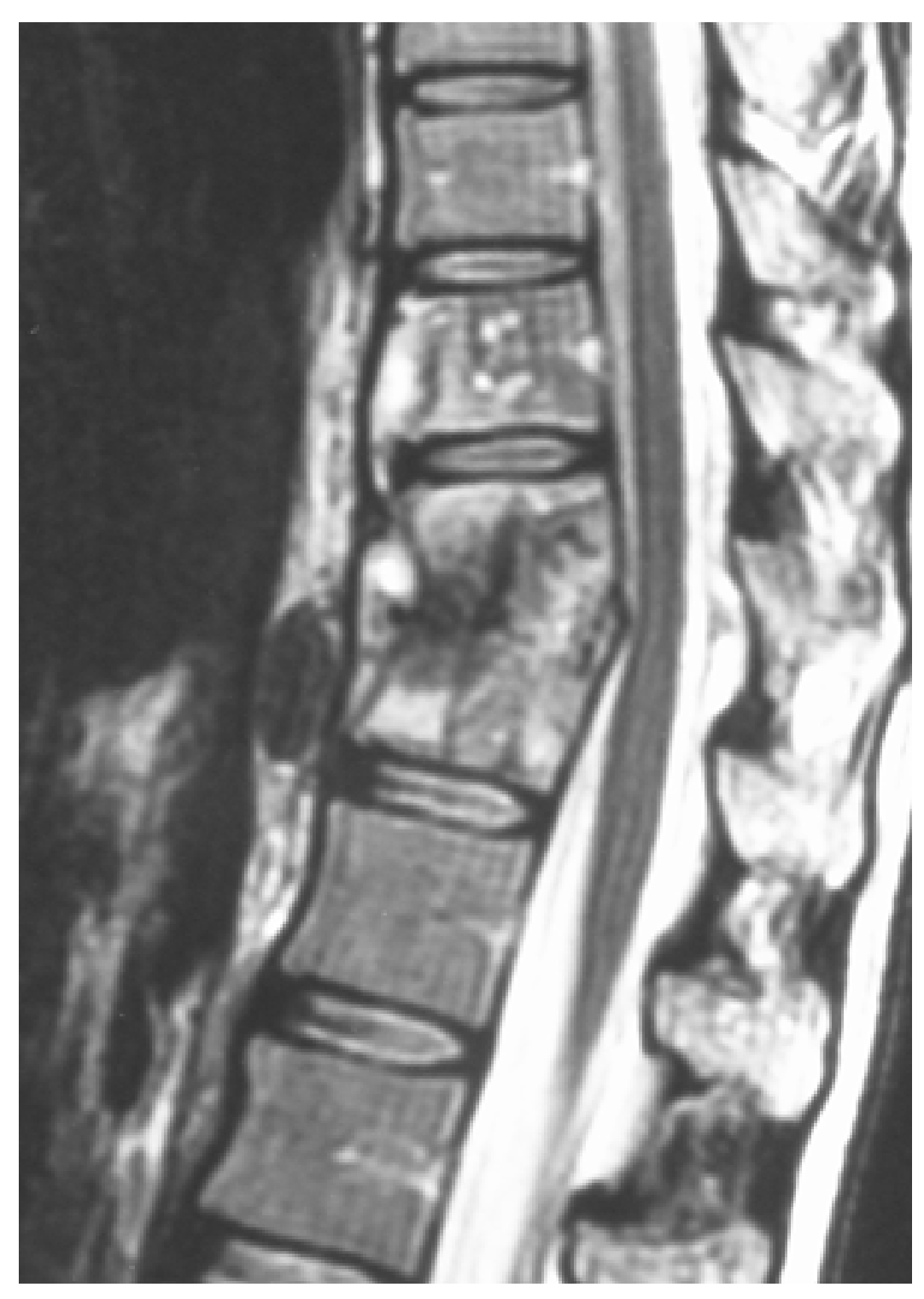

Fig 2B 